\title{
Analysis on the Main Bearing's Lubrication of Internal Combustion Engine Under the Impact
}

\author{
Zhao Jianhua \\ Naval University of Engineering \\ Power Engineering College \\ Wuhan, china, 18971126570 \\ zhaojh402@sina.com
}

\author{
Zhu Debin \\ Naval University of Engineering \\ Power Engineering College \\ Wuhan, china, 15527867463 \\ zhudebin@yeah.ne
}

\author{
Sun Yunpeng \\ Naval University of Engineering \\ Power Engineering College \\ Wuhan, china
}

\begin{abstract}
Studying for the crankshaft-bearing system of a diesel engine in this paper, using the software of AVL-EXCITE, set up the coupled multi-body dynamics simulation system of the crankshaft and bearings, the characteristics of oil film on main bearing were analyzed when the crankshaft under different impact loading. While, taking full account of the speed and the clearance of bearing impact on the lubrication performance of bearing .Working out the changes of main bearing's minimum oil-film thickness and maximum oil-film pressure with crank angle and the orbits of the main-journal center. By studying of the impact stiffness of the bearing's oil film to export the contact between the crankshaft and the body, and lay the foundation for building the whole diesel engine model and the assessment of impact and the optimal design, so as to further improve the impact resistance of the diesel engine .which has great significance to improve the vitality of the diesel engine.
\end{abstract}

Keywords-oil film; the clearance of bearing ; minimum oilfilm thickness; locus of center

\section{INTRODUCTION}

Crankshaft-bearing system of the internal combustion engine is mainly consisted of the crankshaft and the main bearing that is the major moving sport and the friction pair. The working reliability of the internal combustion engine has close relationship with the crankshaft-bearing system. Along with the development of the internal-combustion engine, its index is continuously improved and the crankshaft-bearing system has more bad working conditions. Especially when the promote shaft is absorbed with the strong impact load, it's more outstanding that the resistance performance of crankshaft is influence to reliability of the machine. In order to more step closer to the real, it is necessary to establish the contact with oil film in this system and consider the oil-film's influence with the transfer and response of impact. So must fully research the impact characteristics of the oil film in bearing.

At present, domestic and international research on the crankshaft's impact resistance generally ignored the impact of the film or that in the case of smaller impact given the impact of the stiffness characteristics. Yi Tai-lian designed a set of impact test device of diesel engine's crankshaft-sliding bearing and has done experiments to study the variation of the film impact stiffness, but because of the smaller impact strength, failure mechanism of the film ${ }^{[1]}$. In this paper we establish the

The work presented in this paper was supported by the 12th national defence researching fund of China (No.4010304030202)
Crankshaft-bearing system simulation model based on the AVL-EXCITE software and explore a greater impact on the role of film characteristics.

\section{THE KINETIC THEORY OF OIL FILM LUBRICATION}

The role of the liquid lubricant film can be described by Reynolds equation ${ }^{[2]}$, whenever bearing in any position the film Reynolds equation is:

$$
\begin{aligned}
& \frac{1}{R^{2}} \frac{\partial}{\partial \theta}\left(\frac{h^{3}}{12 \mu} \frac{\partial p}{\partial \theta}\right)+\frac{\partial}{\partial z}\left(\frac{h^{3}}{12 \mu} \frac{\partial p}{\partial z}\right)=\frac{1}{2} \omega \frac{\partial h}{\partial \theta}+\frac{\partial h}{\partial t} \\
& h=h_{0}+\Delta h=h_{0}+\Delta x \sin \theta-\Delta y \cos \theta
\end{aligned}
$$

Where, $\quad h_{0}=C\left[1+\varepsilon_{0} \cos \left(\theta-\phi_{0}\right)\right], \quad \varepsilon_{0}=e_{0} / C$ mean eccentricity, $C$ is show the average radius gap of bearing. $\theta$ and $Z$ are the circumferential and axial coordinates of bearing, $R$ is the journal radius, $\mu$ is the viscosity of the lubricant, $\omega$ is the tangential velocity of the journal.

The film pressure can be written as:

$$
\begin{aligned}
p & =p_{0}+\Delta p \\
& =p_{0}+\left.\frac{\partial p}{\partial x}\right|_{0} \Delta x+\left.\frac{\partial p}{\partial y}\right|_{0} \Delta y+\left.\frac{\partial p}{\partial x_{0}}\right|_{0} \&+\frac{\partial p}{\partial \& t_{0}} \Delta y
\end{aligned}
$$

This is the basis of all theory, if the location and movement of the journal and bearing is known, using the method of finite difference for solving the bearing oil film pressure distribution law. On the contrary, the movement of the journal can be calculated. This calculation method is based on the balance that the carrying capacity of the oil film and the external force, also applies to the load that is non-steady-state.

\section{SIMULATION MODELING AND ANALYSIS OF A COMBUSTION ENGINE OIL-FILM’S IMPACT}

\section{A. Dynamics Simulation Model of the Crankshaft - bearing System}

Using the software of AVL-EXCITE PU, we create a dynamic simulation model that including the body, crankshaft bearings and the crankshaft journal. Among them, the flexible body model of the body using hexahedral mesh, and reduced 
by the finite subspace structure to retain the bearing aperture of nodes and degrees of freedom, as shown in Figure 1 (a). Bearing of Crankshaft using the type of EHD2 model, the model can fully consider the characteristics of the nonlinear oil film, bearing geometry, deformation bearing and filling rate of oil and so on that can affect to the performance of bearing ${ }^{[3]}$. The EXCITE dynamics model of the Crankshaft - bearing system as Figure 1 (b) shown. The main performance parameters of the Crankshaft - bearing system is shown in Table 1.

TABLE I. PARAMETERS OF THE ENGINE

\begin{tabular}{l|l|l|l|l}
\hline $\begin{array}{c}\text { Cylinder } \\
\text { bore/mm }\end{array}$ & $\begin{array}{c}\text { The } \\
\text { calibration } \\
\text { conditions } \\
\text { speed } / \mathbf{r} / \mathbf{m i n}\end{array}$ & $\begin{array}{c}\text { The maximum } \\
\text { torque speed } \\
/ \mathbf{r} / \mathbf{m i n}\end{array}$ & $\begin{array}{c}\text { Oil } \\
\text { pressure } \\
/ \text { par }\end{array}$ & $\begin{array}{c}\text { Mass } \\
/ \mathbf{k g}\end{array}$ \\
\hline 60 & 2300 & 1500 & 5 & 100 \\
\hline
\end{tabular}

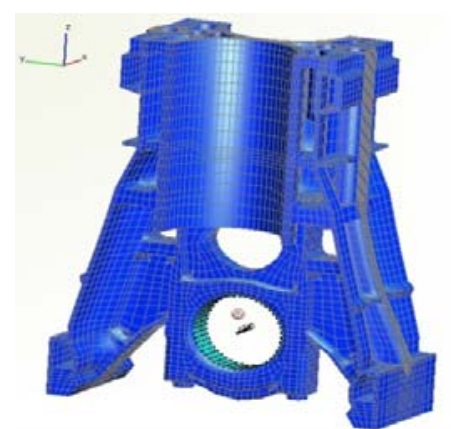

(a)Finite element model of the body

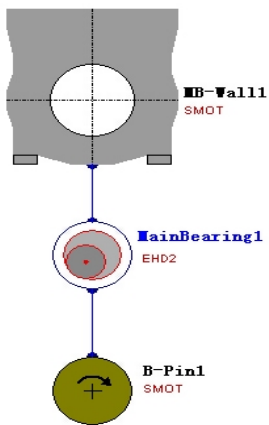

(b)The EXCITE dynamics model

Figure 1. Finite element model of the body and the EXCITE dynamics model

\section{B. The external load}

Choose the standard of German BV043/73, the standard also gives the shape of shock wave, the impact magnitude and the impact time that are required for the design and calculations of impact ${ }^{[4]}$. The curve of shock acceleration with time is shown in Figure 2. The maximum acceleration is $700 \mathrm{~m} / \mathrm{s}^{2}$. To establish a model by AVL-EXCITE, enter parameters about the type of oil, pressure and temperature and then to analyze, get the curve of bearing minimum film thickness, maximum film pressure and the axis of the spindle neck track to analyze the impact response of the film. The film features close contact with the speed and bearing clearance, the paper focuses on these two aspects to analyze the film's impact properties.

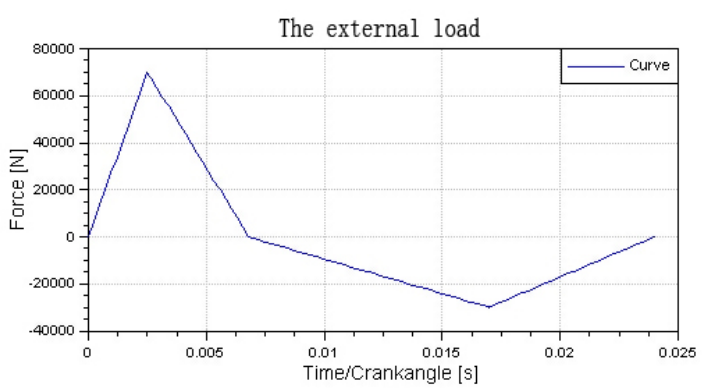

Figure 2. The curve of Impact acceleration with time

\section{Simulation Results and Analysis \\ 1) The affect of Impact strength}

In order to fully understand the reasons for bearing become invalid, we analyze and calculate under the different impact strength. Experiments show that the oil film is smaller effect under the conditions of a small impact. So in this paper, at the calibration speed of working conditions, the impact strength is gradual increased, and get the changing curve of the bearing oil film pressure, minimum film thickness and the axis orbit. The result is shown in Figure 3 and Figure 4.
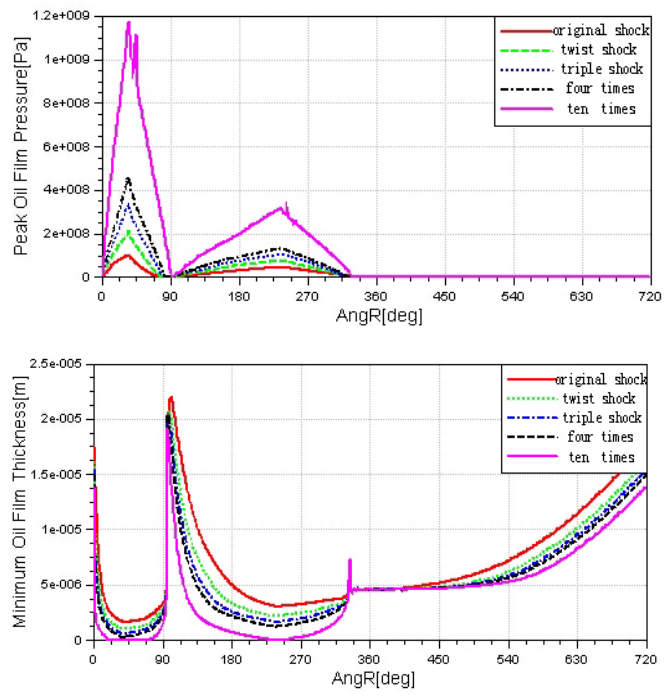

Figure 3. the maximum oil film pressure and minimum film thickness under the different impact strength

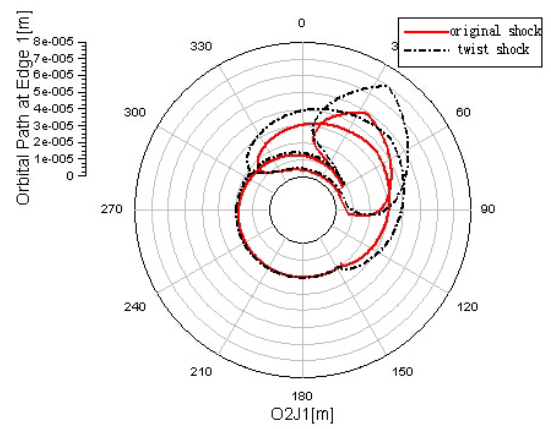



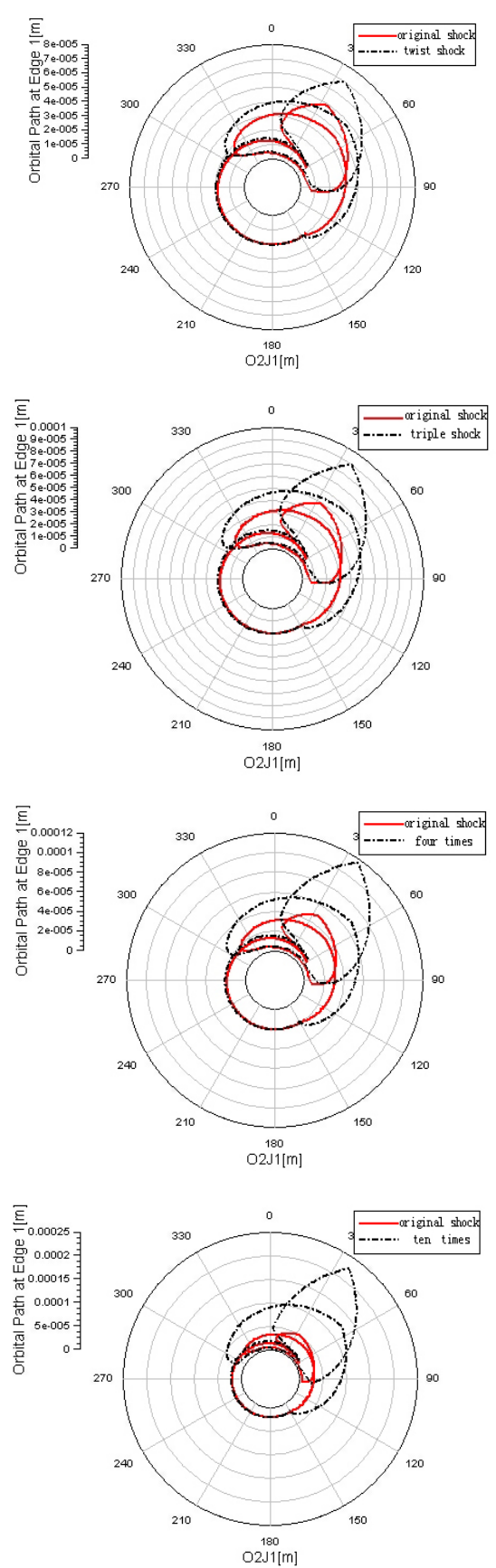

Figure 4. The axis orbit under the different impact strength

From the results we can be drawn that it have verified that the small impact strength has little effect on the minimum film thickness in bearings, but with the increase of intensity, reflecting the eccentric trajectory of the main journal over the general assembly that will cause the main journal collide the bearing, the film is burst, the bearing hole become non-circular, exacerbated by bearing friction leading to reduce the reliability of the main bearing and shorten the life of machine.

\section{2) The affect of speed}

The actual work process of the internal combustion engine has some different loads, it'll be need to operate at different speeds, and speed is critical for the shock stiffness of the oil film. In this study, the operation condition of the internal combustion engine is calculated: the maximum torque speed is $1500 \mathrm{r} / \mathrm{min}$, the standard operating mode speed is $2300 \mathrm{r} / \mathrm{min}$, the maximum speed is $3000 \mathrm{r} / \mathrm{min}$. At the same time, choose the low speed of $1000 \mathrm{r} / \mathrm{min}$ to analyze. The change of the maximum oil film pressure and the minimum film thickness with the different speeds were shown in Figure 5.
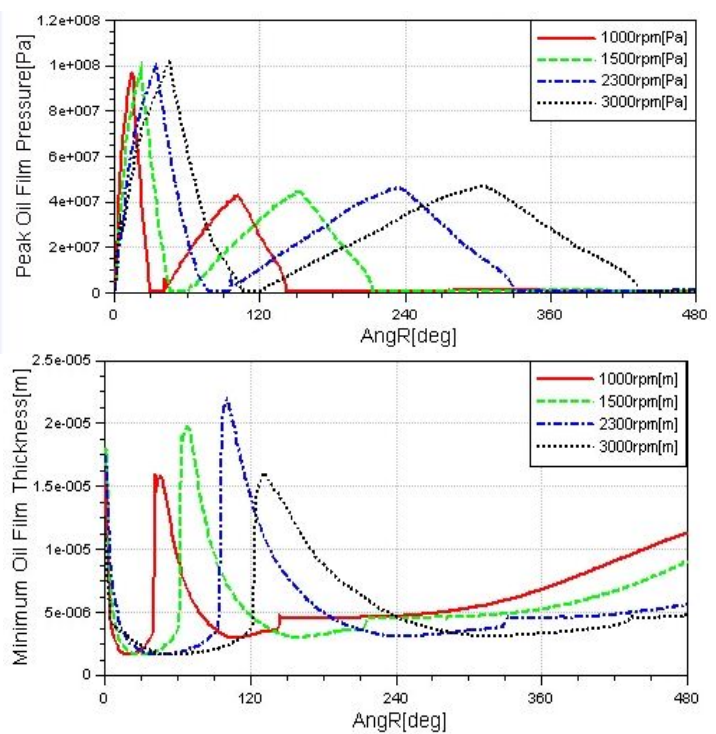

Figure 5. The peak oil film pressure and minimum film thickness change with the different speeds

What can be concluded from the figure that the impact conditions, the change of peak oil film pressure with the increased speed is little, but the minimum film thickness is firstly increases and then decreases with the increased speed. Thus in order to improve the life of the bearing, the rotational speed of the normal work can't be too low, but not long-term over-speed work.

\section{3) The influence of bearing clearance}

The size of bearing radial clearance is greatly affect for the fatigue life of bearing, temperature rise, noise, vibration and other properties. The gap is too large can cause vibration and noise increased, the gap is too small bring about the force of friction is increased and thus not conducive to heat. In this paper, with the same shock and speed, we selected the bearing clearance of $0.015 \mathrm{~mm}, 0.025 \mathrm{~mm}, 0.035 \mathrm{~mm}, 0.045 \mathrm{~mm}$ and $0.1 \mathrm{~mm}$ to calculate and analyze. Its' peak oil film pressure and minimum film thickness are shown in Figure 6.

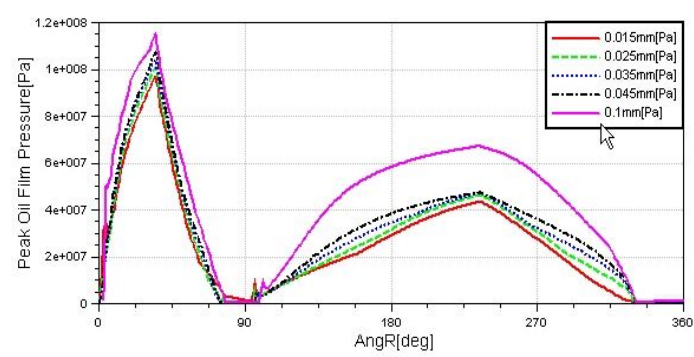




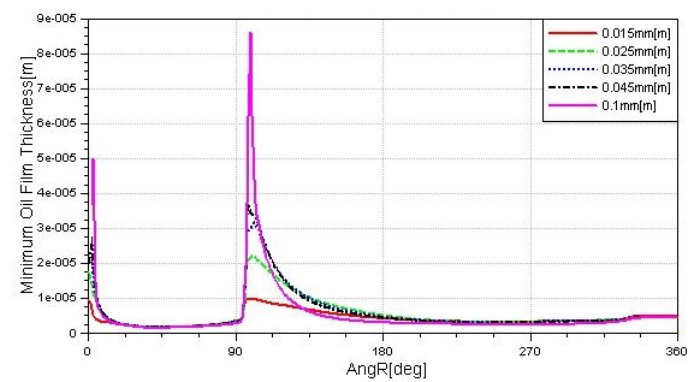

Figure 6. Peak oil film pressure and minimum film thickness change with the different bearing clearance

The figure shows that the maximum oil film pressure of the main bearing increases with increasing bearing clearance, the minimum film thickness with increasing bearing clearance is firstly increases and then decreases. This is because the bearing clearance is too small so that the lubricant film is not easy to form, while the bearing clearance is too large will cause the impact force is increased in the work that undermined the oil film. Therefore, the bearing clearance must be maintained within a certain range in order to achieve good lubrication.

\section{CONCLUSION}

In this study, the shock experiment device of the crankshaft-sliding bearing is established by the AVL-EXCITE software. Its' control equations take consider of the elastic of bearing structure, the movement of oil film and the journal dynamics at the external load. Researching the affect that different impact strength, speed and bearing clearance on the stiffness of the oil film and getting more realistic calculations, derived from the main research results are summarized as follows:

a) Through the simulation of the different impact strength obtained that the performance of the bearing oil film lubrication is less effect in a smaller impact conditions. But beyond a certain extent, the film burst, the force of friction increases, then leading to the bearing become ineffective.

b) With the increase of engine speed, the minimum film thickness of the oil film increases firstly and then decreases. In order to improve the life of the bearing, so the speed can't too low, also can't be over-speed at long time.

c) The minimum film thickness of the bearing oil film with increasing the bearing clearance first increases and then decreases. In order to keep the bearings working, under the premise that the certain temperature of lubricating oil, you must select the right clearance of bearing. With the bearing is used too long, the gap of bearing increases and the impact stiffness of the film decreases, so need to replace the bearings in time.

\section{REFERENCES}

[1] Yi tian-lian, "Study on the Shock Resistance of the Crankshaft Supported with Sliding Bearing " $[\mathrm{J}]$. learned journal of Internal combustion engine, 2007, pp.68-73.

[2] Zhang zhi-ming, “The hydrodynamic lubrication theory of sliding bearings”[M]. in Beijing, Publishing House of the Higher Education 1986.

[3] EXCITE_EHD_ReferenceManual. June. 2004.

[4] BV0430/85, the security of Impact [S]. Germany : German federal defense equipment procurement agency, 1985. 